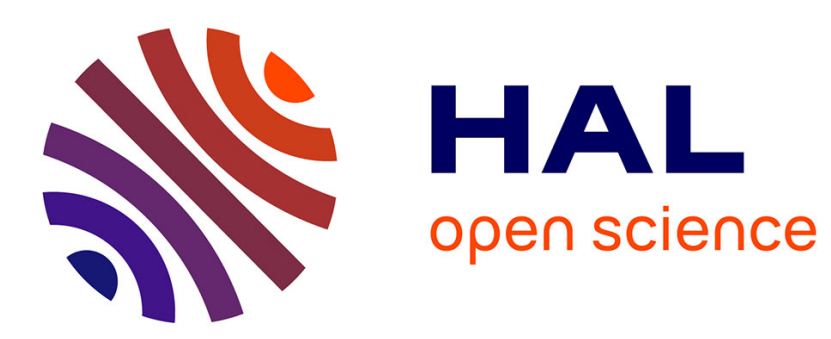

\title{
Environmentally induced mechanical feedback in locomotion: Frog performance as a model
}

\author{
Peter Aerts, Sandra Nauwelaerts
}

\section{To cite this version:}

Peter Aerts, Sandra Nauwelaerts. Environmentally induced mechanical feedback in locomotion: Frog performance as a model. Journal of Theoretical Biology, 2009, 261 (3), pp.372. 10.1016/j.jtbi.2009.07.042 . hal-00554640

\section{HAL Id: hal-00554640 \\ https://hal.science/hal-00554640}

Submitted on 11 Jan 2011

HAL is a multi-disciplinary open access archive for the deposit and dissemination of scientific research documents, whether they are published or not. The documents may come from teaching and research institutions in France or abroad, or from public or private research centers.
L'archive ouverte pluridisciplinaire HAL, est destinée au dépôt et à la diffusion de documents scientifiques de niveau recherche, publiés ou non, émanant des établissements d'enseignement et de recherche français ou étrangers, des laboratoires publics ou privés. 


\section{Author's Accepted Manuscript}

Environmentally induced mechanical feedback in locomotion: Frog performance as a model

Peter Aerts, Sandra Nauwelaerts

PII: S0022-5193(09)00332-4

DOI: doi:10.1016/j.jtbi.2009.07.042

Reference: YJTBI 5637

To appear in: $\quad$ Journal of Theoretical Biology

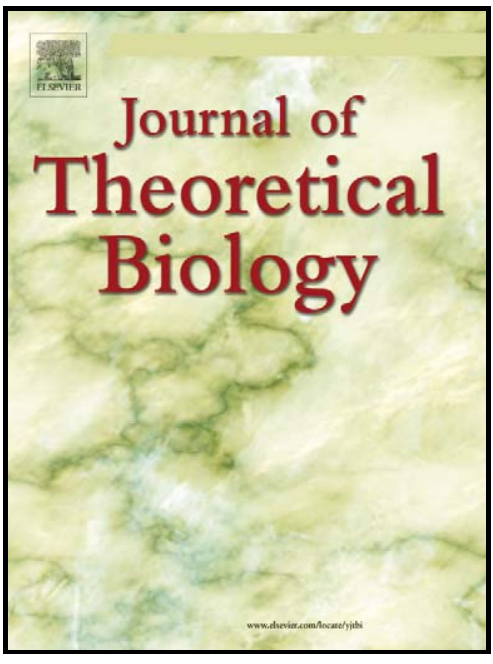

www.elsevier.com/locate/yjtbi

Received date: $\quad 24$ September 2008

Revised date: 13 July 2009

Accepted date: 14 July 2009

Cite this article as: Peter Aerts and Sandra Nauwelaerts, Environmentally induced mechanical feedback in locomotion: Frog performance as a model, Journal of Theoretical Biology, doi:10.1016/j.jtbi.2009.07.042

This is a PDF file of an unedited manuscript that has been accepted for publication. As a service to our customers we are providing this early version of the manuscript. The manuscript will undergo copyediting, typesetting, and review of the resulting galley proof before it is published in its final citable form. Please note that during the production process errors may be discovered which could affect the content, and all legal disclaimers that apply to the journal pertain. 


\title{
Environmentally induced mechanical feedback in locomotion: frog performance as a model
}

\author{
by \\ Peter AERTS ${ }^{1,2} \&$ Sandra NAUWELAERTS ${ }^{1,3}$ \\ ${ }^{1}$ Laboratory of Functional Morphology, Department of Biology, University of Antwerp, \\ Belgium \\ ${ }^{2}$ Department of movement and sport sciences, University Ghent, Belgium \\ ${ }^{3}$ McPhail Equine Performance Center, Michigan State University, US
}

Running title: effect of mechanical feedback in locomotion

Address of correspondence

Peter AERTS

Laboratory of Functional Morphology

Department of Biology (CDE)

University of Antwerp

Univeristeitsplein 1

B-2610 Wilrijk (Antwerpen)

Belgium 


\begin{abstract}
At first glance, the strategy for generating propulsive impulses for both jumping and swimming in frogs is quite similar. Both modes rely on powerful extension of the hind limbs. However, in Rana esculenta (the semi-aquatic green frog), propulsive impulses for jumping were found to be much larger than those generated during swimming (Nauwelaerts and Aerts, 2003). The hypothesis that differences in propulsive impulse between swimming and jumping are largely caused by specific environmental constraints rather than being due to changes in motor control is tested in the present study. To assess this question, the actuator of a simple mathematical model, mimicking a frog with symmetrically kicking hind limbs, is first tuned to perform frog-like jumps. Next, the same actuator activation is applied to drive the model in an 'aquatic environment'. Despite the entirely identical activation, the resulting in silico propulsive swimming impulse was less than half that produced during jumping, just as observed in vivo. Although duration of limb extension is similar for both locomotor modes (both in vivo and in silico), this conspicuous difference in model behaviour is entirely explained by the actuator working at different positions along its force-velocity curve. These findings suggest that the same environmentally induced effects are also involved in real swimming and jumping as well, thus explaining the apparent difference in performance level.
\end{abstract}

Keywords: neuromechanics, motor control, frog locomotion, performance, physical properties environment 


\section{Introduction}

Irrespective of the locomotor mode, propulsion relies upon forces exerted by the animal on its environment. The inherent reaction, together with the other external forces acting on the animal (gravity, resistive forces), rules the instantaneous dynamics of the animal's body and, consequently, the nature of the resulting motion. Overall performance is determined by the sum of the propulsive impulse(s) (i.e. opposite of the time integral of forces actively generated by the animal) and the impulses of the mentioned external forces applied over a complete locomotor cycle (Nauwelaerts and Aerts, 2003).

At first glance, the strategy for generating the propulsive impulses for jumping and swimming in frogs is quite similar. Both modes rely on powerful extension of the hind limbs. When jumping from a rigid surface, this extension is directly translated in momentum increase of the animal's body. In water, similar forceful extensions of the hind limbs accelerate water backwards (Johansson and Lauder, 2004; Nauwelaerts et al., 2005a,b; Richards, 2008). The resulting reactive forces propel the animal in its swimming cycle.

Nauwelaerts and Aerts (2003) calculated propulsive impulses for jumping and swimming in Rana esculenta, the semi-aquatic green frog. Jumping impulses were much larger than those generated during swimming, even if the animals were chased vigorously to induce maximal swimming performance (thus excluding the issue of 'motivation'; see Fig. 4). This difference in impulse (essentially being 'force $\mathrm{x}$ time') results primarily from a lower force production and much less from a shortened duration of leg extension during swimming (Nauwelaerts and Aerts, 2003; see also Nauwelaerts et al., 2005a,b; Stamhuis and Nauwelaerts, 2005).

When examined in detail, subtle (but significant) postural differences and differences in joint kinematics between jumping and swimming were evidenced (Nauwelaerts and Aerts, 2003), and our ongoing EMG-analyses reveal obvious shifts in the activation patterns of the major limb extensors in Rana esculenta. These findings accord to the conclusions drawn from earlier studies which compare jumping and swimming in other anurans (Kamel et al., 1996; Gillis and Biewener, 2000; Gillis and Blob, 2001; but see Emerson and De Jongh, 1980). Thus, the divergence between jumping and swimming impulses must seemingly be attributed to differences in the neuronal hind limb control, an assumption that is likely reinforced by the fact that no correlations could be detected between individual maximal jumping and swimming performance (Nauwelaerts et al., 2007; Nauwelaerts et al., 2005a). 
Yet, mechanical constraints imposed by the environment differ drastically for anurans when jumping and swimming. When swimming, limbs do not push against a rigid support. Moreover, water is 50 times more viscous and 800 times denser than air (Denny, 1993) and when submerged, hydrostatic lift forces largely counteract gravitational forces. Therefore, mechanical feedback imposed by the environment will probably also differ between both locomotor modes. As such feedback can affect the mechanical output of the extensor muscles directly and independently from neuronal control (for instance via intrinsic force-velocity relationships), a direct effect of these environmental differences on propulsive impulse generation cannot be excluded a priori. Such a non-neuronal effect is similar to the so-called preflexive responses to mechanical perturbations (Brown and Loeb, 2000; Full and Kodischeck, 1999; Nishikawa et al., 2007).

Experimentally discriminating between the share of mechanical feedback and that of central steering or reflexive adjustments of the motor pattern (cf. above) in the reduced propulsive impulse generation of swimming is impossible. In order to do so, individual impulses generated during jumping, during unconstrained swimming (i.e. natural behaviour) and during 'imposed swimming' (i.e. swimming with imposed, non-modulated extensor activation patterns identical to those used for jumping) should be compared. The difference between 'imposed' and unconstrained swimming impulses would reflect impulse reduction resulting from altered hind limb control; the difference between the jumping impulses and imposed swimming impulses would reflect the direct effect of environmentally induced mechanical feedback. Obviously, 'non-modulated jump-style swimming' cannot be imposed in vivo.

The framework of the present contribution is the neuromechanical point of view on motor control: observed motor behaviour emerges from the interaction between neuronal steering and intrinsic mechanics (dynamics) of the system and the environment. In this paper, we aim to explore, theoretically, the extent to which environmentally induced mechanical feedback can potentially play a role in the shifts between terrestrial and aquatic locomotor performance as observed in the green frog (Nauwelaerts \& Aerts, 2003). Is the potential effect, attributing the observed impulse reduction (i.e. the collective output of the system) primarily to shifts in neuronal hind limb control (including neuronal feedback) marginal? Or, is it, on the contrary, a potentially important explanatory factor in the observed phenomenon (reduction of the collective output of the system)? For this purpose, a simple mathematical frog-model will be applied. A limb actuator with muscle-like properties will be activated identically, in both the aquatic and terrestrial environment. In silico propulsive force profiles 
and impulses will be calculated and used to evaluate the importance of environmentally induced mechanical feedback in the performance of the living frogs.

\section{Methods: Model description}

The model was deliberately kept simple, yet mimicking a frog with symmetrically kicking hind limbs. Its 'morphology' consists of an ellipsoid body and a mass-less telescopic limb. The feet are plate-like and oriented perpendicularly to this limb (see Fig.1).

The telescopically extending limb is driven by an actuator with a velocity dependent force output (see Fig.2A; Hill's force-velocity-relationship):

$$
F_{\text {actuator }(t)}=F_{\max } \frac{\left(V_{\max }-V_{\text {actuator }(t)}\right)}{\left(V_{\max }+G V_{\text {actuator }(t)}\right)} \quad(\text { Alexander, 2003a) }
$$

[with $F_{\max }=$ maximal isometric force of the actuator; $F_{\text {actuator }(t)}=$ instantaneous actuator force; $V_{\max }=$ maximal speed of the actuator; $V_{\text {actuator }(t)}=$ instantaneous actuator speed; $G=$ shape factor $=4$ (i.e. typical value for vertebrate muscle, Alexander, 2003a)]. There is no effect of actuator length on force output (i.e. the muscle-like actuator always works at optimal 'filament' overlap; Lutz and Rome, 1994) and visco-elastic behaviour of attachment structures is not considered. The actuator limb can extend $0.09 \mathrm{~m}$ (about the total length of the anatomical hind limb, see table 1) according to what occurs during the jumping push-off (hind limb segments are completely extended immediately prior to take off in maximal jumps; Nauwelaerts \& Aerts, 2003). Full-scale activation of the actuator builds up gradually and smoothly (modelled as a sine-function) and is reached in 0.02s [see Fig.2B; cf. the control records presented in Cecchi et al. (1981)]. The active state declines similarly over the time period coinciding with the final 10\% of limb extension (limb length triggered; Fig.2B). 3333Forward dynamical modelling of a single kick is carried out numerically (Euler integration) with time steps equal to $5 \times 10^{-4} \mathrm{~s}$. The general equation of motion used for both body and feet is:

$$
\text { 'mass'. } a_{(t)}=F_{\text {actuator }(t)}+F_{\text {resistive }(t)},
$$

[with 'mass' $=$ the representative mass (see further); $a_{(t)}=$ the instantaneous acceleration of respectively body and feet; $F_{\text {actuator }(t)}=$ the instantaneous force of the actuator given by (1); $F_{\text {resistive }(t)}=$ forces acting against the movement of respectively body and feet; note that $F_{\text {actuator }(t)}$ and $F_{\text {resistive }(t)}$ are normally opposite in sign]. 
For jumping, $F_{\text {actuator(t) }}$ and $F_{\text {resistive( }(t)}$ at the feet cancel each other out (i.e. pushing against a rigid surface), so that the above equation of motion only needs to be solved for the body. In this case, 'mass' $=$ body mass (cf. table 1) and $F_{\text {resistive }(t)}=\left(-9.81 \mathrm{~m} / \mathrm{s}^{2}\right)$ body mass, since (i) air resistance is neglected and (ii) the model jumps vertically for reasons of simplicity.

During swimming the general equation of motion (2) is solved for both the ellipsoid body and the plate-like feet. For the body, 'mass' $=(1+a d d)$ body mass, with add an added mass factor equal to 0.2 (i.e. an add for an ellipsoid with frog-like proportions; Daniel, 1984). $\mathrm{F}_{\text {resistive }(t)}$ for the body is given by:

$$
F_{\text {resistive }(t)}=\frac{1}{2} \rho A V^{2} \operatorname{body}(t) C d,
$$

[with $\rho=$ density of the water $\left(1000 \mathrm{~kg} / \mathrm{m}^{3}\right) ; A=$ representative surface area (see further);

$V_{b o d y(t)}=$ instantaneous velocity of the body; $C d=$ drag coefficient corresponding the representative $A]$. The $C d$ used for the calculations was determined experimentally from the deceleration of the body during the coasting phase of 26 video-taped sequences of swimming frogs (see Nauwelaerts \& Aerts, 2003). When coasting, $F_{\text {actuator }(t)}$ equals zero, enabling us to solve equation (2) for $C d$. Making use of $\mathrm{SVL}^{2}$ (cf. table 1) as representative surface area (SVL being an easy measure on living frogs), this procedure resulted in $C d=0.14$. This $A$ and its according $C d$ were used for the present forward modelling. Gravitational forces and hydrostatic lift forces were not considered as these are assumed to cancel each other out.

$F_{\text {actuator }(t)}$ also acts on the feet. The 'mass' in equation (2) is now considered to be that of an ellipsoid volume of water moving with each of the kicking feet as evidenced recently by means of digital partical image velocimetry (DPIV; Stamhuis and Nauwelaerts, 2005;

Nauwelaerts et al.,2005a,b; see also Johansson and Lauder, 2004;). The ellipsoid dimensions are such that the long axis equals the total length of the foot (cf. table 1), whereas both other axes are equal in length, the latter being set by the surface area of the foot equating the crosssectional ellipse (see table 1).

An equation similar to (3) is used to determine the $F_{\text {resistive }(t)}$ on each foot. In this case, $A$ equals the foot surface area (see table 1) and $V_{b o d y(t)}$ in (3) is replaced by $V_{\text {foot }(t)}$ (instantaneous velocity of the foot; negative when moving backwards). As the foot surface is slightly cambered during the kick, the $C d$ of a hollow hemisphere (concave side against the flow; $C d=1.42$; Hughes and Brighton, 1999) is taken as a useful approximation. If the modeled kick represents the propulsive phase of a swimming cycle in a series, the feet may 
initially have a forward velocity (see Fig.3B), which means that $C d$ drops to approximately one fourth of this value (hollow hemisphere, convex side against the flow; Hughes and Brighton, 1999) and that $F_{\text {resistive( }(t)}$ actually assists extension of the limbs during such an initial phase.

For each computational iteration, the accelerations of body and feet were determined [equation (2)], and used to obtain the according velocities and displacements of these segments over the according time interval (integration). From these variables, the instantaneous length and velocity of the actuator $V_{\text {actuator }(t)}$ was calculated. This $V_{\text {actuator }(t)}$ was entered in equation (1) to get $F_{\text {actuator }(t)}$ for the next time-step, taking into account its active state (as presented in Fig. 2B; see above). Thus, time profiles of $F_{\text {actuator }(t)}$, $V_{\text {actuator }(t),} V_{\text {body }(t)}$, $V_{f o o t}(t)$ and the displacements of body and feet were framed until full extension. Duration of the kick and velocity gain of the body could be deduced from these time profiles. The time integral of the $F_{\text {actuator }(t)}$ yielded the propulsive impulse.

\section{Results}

\section{Simulation 1: representative jumping}

Given the morphometrics as presented in table $1, F_{\max }$ and $V_{\max }$ in the force-velocity relationship (equation (1)) were adjusted to perform a frog-like jump. Iterations were run until the duration of the push-off (i.e. full limb extension) as well as maximal velocity at the end of the push-off corresponded to the average of the jumps (collected at 20-22 ${ }^{\circ} \mathrm{C}$ ) used to calculate the in vivo impulses in Nauwelaerts and Aerts (2003; see also figure 4). This was achieved with $F_{\max }=20$ body weights and $V_{\max }=20$ total extension lengths/s. With isometric muscle stress typically equal to 0.3 MPa (e.g. Marsh, 1994; Alexander, 2003a; Biewener, 2003) this actuator $F_{\max }$ would accord to a total physiological extensor cross section of approximately $0.13 \mathrm{~cm}^{2}$, which is realistic for a green frog (Nauwelaerts et al., 2007). Given the telescopic nature of the actuator, the equivalent length of the theoretical 'muscle fibres' of the actuator exceeded its extension length many times. Consequently, the maximal intrinsic 'muscle speed' ( $V_{\text {max-fibre }} /$ fibre length) was below $20 \mathrm{~s}^{-1}$, well within the physiological range of (frog) muscle properties (e.g. Alexander, 2003a; Woledge et al., 1985).

Using these actuator settings, the jump push-off took $0.0915 \mathrm{~s}$ and resulted in a takeoff speed of $1.36 \mathrm{~m} / \mathrm{s}$, very similar to the in vivo measurements presented in Nauwelaerts and 
Aerts (2003). Peak force equalled $1.307 \mathrm{~N}$ (almost identical to the average of the measured take-off peak vertical forces in jumping green frogs; Nauwelaerts and Aerts, 2006). The propulsive impulse (i.e. the surface area bounded by the force profile for jumping in figure 3A) was $0.045 \mathrm{Ns}$, which accords to the measured jumping impulses as presented in Nauwelaerts and Aerts (2003; see also Fig. 4).

Note that the profile shape of the ground reaction forces produced by the single linear actuator limb (identical to the actuator force profile) differs from the force traces produced by jumping frogs (e.g. Calow and Alexander, 1973; Peplowski and Marsh, 1997; Marsh, 1994, Olson and Marsh, 1998; Roberts and Marsh, 2003; Nauwelaerts et al., 2005a,b; Wilson et al., 2000). This is not surprising because in reality, displacements of the body result from coordinated rotations of the limb-joints in a proximo-distal sequence (Nauwelaerts and Aerts, 2003), the typical coordination in jumping vertebrates (e.g. Aerts, 1998; Bobbert et al., 1986a,b). As impulse equals the change in momentum and the actuator settings are tuned on take-off speed (and push-off duration), the impulse estimate is reliable.

\section{Simulation 2: swimming}

The same $F_{\max }$ and $V_{\max }$ and morphometrics are used to simulate the propulsive kick of a swimming cycle in a series, for which the forward velocity at the onset of limb extension equals $0.1 \mathrm{~m} / \mathrm{s}$. The latter condition compares to the in vivo swimming cycles used for the impulse calculations in Nauwelaerts and Aerts (2003; see also Fig.4). The time profile of the actuator force is presented in figure 3A. Given that limb joints in swimming frogs extend more or less simultaneously (Nauwelaerts and Aerts, 2003), the telescopic actuator represents a better mimic (cf.jumping) and the simulated force profiles are similar to the actual force patterns as deduced from experimental hydrodynamical analysis (DPIV; see Nauwelaerts et al., 2005b).

Despite the identical activation level of the actuator, force output clearly diminishes when performing in the aquatic environment (Fig. 3A). The propulsive kick takes $0.0775 \mathrm{~s}$ (which is well within the range of measured durations of propulsion during swimming; Nauwelaerts and Aerts, 2003; see Fig.4). The resulting increase in velocity is $0.69 \mathrm{~m} / \mathrm{s}$, which is similar to recorded maximal performances (Nauwelaerts and Aerts, 2003). Peak force falls to $0.449 \mathrm{~N}$ (about 1/3 of the jumping force). The propulsive impulse, $0.021 \mathrm{Ns}$, is less than half the impulse generated during the jump (see squares in Fig.4). Since the design (morphometry and 'physiology'), as well as motor control (set by the activation level) of the model are 
completely identical for both mimics and since feedback is not included in the model, the emerging decrease in model impulse (performance) is exclusively the result of the dynamical interaction between the model's intrinsic constructional features and the extrinsic environmental factors.

\section{Relating mechanical feedback to (model) performance}

The common neuromechanical view on control is that muscle force is adjusted via muscular activation level, in such a way that the desired movement pattern is obtained. Without feedback, or when maximally activated, however, it is solely the interplay between the instantaneous muscle force as set by the F-V-relationship and the external forces that will determine the speed of motion, hence the speed of muscle shortening. The latter condition applies to the present simulations. As illustrated in figure $3 \mathrm{~A}$, differences in the actuator forces between jumping and swimming emerge primarily, but not exclusively, during the initial phase of activation. As a consequence, and according the Force-Velocity-relationship [equation (1)], actuator velocity is initially considerably higher in the extension for swimming than for jumping (see Fig.5A, C). In swimming, part of this high actuator speed results from the backwards slipping of the feet (cf. significant negative velocities and displacements of the feet during the swimming kick in Fig.3B,C), whereas the forward movement and speed of the body is lower compared to that generated during the jumping push-off. As such, slipping (which is also observed in the real frogs; personal observation) does not explain the lower propulsive forces (hence the reduced propulsive impulse) for swimming. Only when the differential speed of body and feet exceeds the limb extension velocity generated during the jump push-off, will swimming performance (i.e. propulsive impulse) reduce for the modelled frog.

For the (modelled) frog it seems hard to avoid the latter situation. The instantaneous accelerations of body and feet determine how the velocity of the actuator builds up during the kick. According equation (2), these accelerations are determined by the external forces acting on the respective segment and by its inertia:

$$
a_{(t)}=\frac{F_{\text {actuator }(t)}+F_{\text {resistive }(t)}}{\text { 'mass' }} .
$$

In other words, for any given $F_{\text {actuator }(t)}$, the according $a_{(t)}$ (the instantaneous acceleration) will

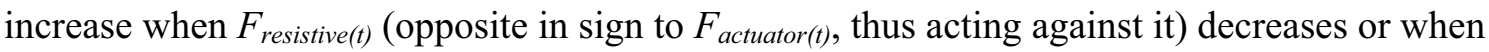
the representative 'mass' becomes lower. 
In jumping, $F_{\text {resistive( } t)}$ on the body is constant and equal to bodyweight $=(-$ $9.81 \mathrm{~m} / \mathrm{s}^{2}$ )body mass (thin green line in Fig. 3A). As it takes time to build up the active state of the actuator (20 ms in the simulations; see Fig. 2A), $F_{\text {actuator }(t)}$ will be smaller than the constant resistive force (= bodyweight) at the beginning. This causes the small initial further flexion of the actuator limb (cf. negative velocity initially in the jump; see Fig.3B). Only after a delay of $12 \mathrm{~ms}$, acceleration results in substantial body displacement (1 $\mathrm{mm}$ forward movement, cf. Fig.3C). At the feet $F_{\text {resistive }(t)}=F_{\text {actuator }(t)}$ (pushing against rigid surface) and $a_{(t)}$ $=0$. Therefore, actuator velocity remains low at the beginning of the jumping kick (see Fig.5A) and force output is high as a consequence [cf. equation (1); see Fig.3A]. When the actuator is fully activated $(\mathrm{t}=20 \mathrm{~ms})$, its velocity is still only half that observed for the swimming kick (see Fig.5A), allowing the actuator to keep on working with a higher force output (see Force-Velocity curve in Fig.5B).

During swimming, however, $F_{\text {resistive }(t)}$ varies with the square of the instantaneous velocity of respectively body and feet [see equation (3); thin red curves in Fig. 3A]. Consequently, when velocities of body and feet are low (especially in the early phase of the swimming kick), $F_{\text {resistive }(t)}$ will be low, too. Thus, $a_{(t)}$ can be expected to be large compared to what occurs in jumping, unless the representative 'mass' involved is equivalently higher.

Given the morphometrics and $C d$ applied for the simulations, equation (3) predicts a $F_{\text {resistive( }(t)}$ for the body which remains significantly below bodyweight throughout the kick $(<50 \%$; see Fig.3A). As the representative 'mass' is only $20 \%$ higher than body mass (i.e. taking account of an added mass factor of 0.2; see Materials and Methods), the acceleration of the body must, compared to jumping, be higher for any given $F_{\text {actuator }(t)}$ [cf. equation (4)]. Yet, the body can never reach the velocities observed for jumping, simply because $F_{\text {actuator }(t)}$ stays well below the forces developed during the jumping push-off for swimming (see Fig.3A).

Similarly, $F_{\text {resistive }(t)}$ at the feet remains smaller than $F_{\text {actuator }(t)}$ (or even takes the same sign) initially during the kick (see Fig.3A) when the velocity of the feet is still low (or is positive in the very beginning for a kick in a series; see above). Moreover, as the representative 'mass' at the feet (the ellipsoid water masses $=2 \rho$ ellipsoid volume) is fairly small (about 25\% of body mass), initial backwards accelerations of the feet must be high (cf. sharp negative velocity increase in Fig.3B). Later in the kick, when the actuator is fully active $(\mathrm{t}>20 \mathrm{~ms}), F_{\text {resistive(t) }}$ becomes slightly larger than the actuator force (Fig.3A) resulting in the small reduction of the negative velocity of the feet (see Fig.3B).

Taking into account the combined effects on body and feet, actuator velocity for swimming must be high (see Fig.5A) and force output must be low (see Fig.3A) compared to 
levels in jumping, especially at the beginning of the kick. It must be noted that, as in the model, real swimming is characterised by a higher extension speed of the limbs compared to jumping (compare Figure 5C and 5A). As a result, the actuator has to work during swimming at the low end of its Force-Velocity curve once it becomes fully activated (Fig.5B). This keeps the forces below the jumping level throughout the kick (see Fig.3A) making the swimming propulsive impulse more than 50\% smaller than the jumping impulse. The fact that the most drastic differences in actuator behaviour occur during the tension rise $(20 \mathrm{~ms}$ in the present simulations; Figs 3A, 5A; the largest difference in actuator speed already occurs at $13 \mathrm{~ms}$ ) probably explains why the total duration of limb extension is affected only to a limited extent (approximately 15\%) by the change in environment.

\section{Discussion}

The present paper does not aim to unravel the mechanics of the musculo-skeletal system of frogs during locomotion. Frog performance is used as a paradigm to explore the extent to which environmentally induced mechanical feedback can potentially attribute to emerging shifts in motor behaviour. For this purpose, terrestrial and aquatic performance in frogs is highly appropriate, because propulsion on land and in water is realized in largely similar ways, i.e. forceful extension of the hind limbs. According Alexander's (2003b) argument that "the simpler the model, the clearer it is which of its features is essential to the calculated effect", the present model deliberately mimics only the fundamental aspect of this propulsive action: a linear kick driven by a single actuator devoid of any neurological feedback. Thus, emerging shifts in the behaviour of the model must be due to the altered mechanical features of the environment.

By virtue of the simplicity of the model, it can be decisively concluded that mechanical feedback from the environment, acting via the intrinsic properties of the muscle systems, is not a marginal factor in the interpretation of motor behaviour and performance level of organisms. In the case of frog performance, used in the present simulation study as the paradigm, Nauwelaerts and Aerts (2003) found a large difference in impulse between jumping and swimming (factor 0.5; see Nauwelaerts et al., 2005b and Stamhuis and Nauwelaerts, 2005 for verification of in vivo measurements of impulses). The present in silico experiments predict that such shifts in propulsive impulse can largely be attributed to the differences in environmental constraints between jumping and swimming. Given the 'frogginess' of the 
model and the high (absolute) similarity between in vivo and in silico impulses (see Fig.4), these findings suggest that the same environmentally induced effects should not be ignored in real swimming and jumping (see for instance also Emerson and De Jongh, 1980).

There is no doubt that the present model utilised to evaluate the impact of environmental mechanical feedback is a considerable simplification of the biological complexity. The above cautious extrapolation towards reality by no means implies that the observed differences in kinematical and muscle activation patterns of swimming and jumping frogs (cf. the Introduction) are irrelevant when explaining the shift in performance. Obviously, altered kinematics and contraction patterns reflect adaptations to the specificity of the tasks (swimming, jumping), and proprio- and exteroceptive neuronal feedback modulation in response to the environmental conditions definitely play their essential role in shaping the intricate details of the locomotor behaviours.

Moreover, it should be evaluated whether the extensive simplification does not affect the conclusions regarding mechanical control, drawn from the model. The first simplification worthy of discussion is the neglect of the length-tension relationship for the actuator (i.e. the implicit assumption that the actuator always acts at the plateau of its length-tension relationship). Including the length-tension (L-T) relationship in the present simulations is irrelevant because the starting configuration and amplitude of the propulsive kick are identical in both circumstances. Thus, the used segment of the length-tension curve is also identical. The assumption that the contraction also proceeds along the ascending or descending segments of the relationship, would for the present model only result in subtle shifts in the shape of the force curve, not in the amplitude, and cannot affect the conclusions. It must further be remarked that Lutz and Rome (1994) argued that in vivo limb extensors in frogs actually act at the plateau of their L-T-curves.

Secondly, the absence of in-series compliance must be addressed. In both simulations, the potential loading of serial elastic components would occur against inertial and resistive (gravity, hydrodynamics) loads. Obviously, including appropriate in-series compliance would have affected the tuning of the model (i.e. establishing the intrinsic force and speed needed to produce the frog-like jump; see Materials and Methods) and consequently the shape of the resulting force profile. However, as identical model settings would have been used for the swimming simulations, profiles would be influenced accordingly, although the series elastic effect would probably have been smaller given the considerably lower actuator forces 
in swimming (Fig. 3A). Regardless, it is obvious that including in- series compliance will not change the present conclusions.

Finally, real frogs do not jump or swim with telescopic limbs driven by a single actuator. In reality, rigid segments rotate at their joints, driven by extensors, to generate the forceful kick and rotation of the feet in the ankle joints contribute to propulsion in both jumping and swimming (e.g. Richards, 2008, Roberts and Marsh, 2003). Adding more complexity, for instance by including hip, knee and ankle joints each driven by a single extensor, in the present model approach (i.e. first tuning the activation and coordination of the extensors to make the model jump realistically; then using these activation profiles to drive swimming) would be very challenging as the system is then largely underdetermined. This tuning would require an optimisation algorithm to find the muscle activation patterns for a premised optimisation criterion (e.g. realising the jump with minimal energy, or minimal force, or equal force distribution over the extensors...) which is, although definitely interesting, outside the scope of the present study.

An alternative approach would be to start from the known extensor activity instead of tuning the model as explained above. Clearly, simply applying net joint torques, obtained from inverse dynamical analysis of either jumping or swimming [see for instance Richards (2008) for an elegant model of swimming Xепориs], in the forward dynamics modelling of the propulsive kick of the other locomotor mode would not suffice because mechanical feedback via force-velocity (and eventually force-length) relationships is evidently not included in that case. For this purpose, a complex anatomy-based forward model (see for instance Kargo \& Rome, 2002; Kargo et al., 2002), including details such as muscle mechanics, morphometrics (e.g. physiological cross-sections, inertia) and instantaneous moment arms (e.g. Lieber and Brown, 1992), etc., is required. Intensity and timing of the muscle activation should be based on the quantitative analysis of EMG-recordings (e.g. Kamel et al., 1996; Gillis and Biewener, 2000) and identical activation patterns should be applied in a terrestrial and aquatic environment (the later probably requiring intricate CFD application). Obviously, when combined with function analysis of actual jumping and swimming, such a challenging modelling approach may unravel much of the neuromechanics of real frog locomotion and provide better insight into the way the neuromotoric system copes with the changing physical properties of the environment. 


\section{Acknowledgements}

We thank Dr. N. Curtin (Imperial College, London) for the helpful information on muscle properties. 


\section{References}

Aerts, P., 1998. Vertical jumping in Galago senegalensis: the quest for a hidden power amplifier. Philos. Trans. Roy. Soc.B-Biol. Sci. 353, 1607-1620.

Alexander, R.McN., 2003a. Principles of animal locomotion. Princeton University Press.

Alexander, R.McN., 2003b. Modelling approaches in biomechanics. Philos. Trans. R. Soc. BBiol. Sci. 358, 1429-1435.

Biewener, A., 2003. Animal locomotion. Oxford University Press.

Bobbert, M., Huying, P. Van Ingen Schenau, G., 1986a. A model of the human triceps surae muscle-tendon complex applied to jumping. J. Biomech. 19, 887-898.

Bobbert, M., Huying, P. Van Ingen Schenau, G., 1986b. An estimation of the power output and the work done by the triceps surae muscle tendon complex in jumping. J. Biomech. 19, 899-906.

Brown, I., Loeb, G., 2000. A reductionist approach to creating and using neuromusculoskeletal models . In: Winters J., Cargo, P. (eds). Biomechanics and neural control of posture and movement. New York: Springer-Verlag, pp. 148-163.

Calow, L., Alexander, R.McN., 1973. A mechanical analysis of a hind leg of a frog Rana temporaria. J. Zool. 171, 293-321.

Cecchi G., Colomo, F., Lombardi, V., 1981. Force-Velocity relation in deuterium oxidetreated frog single muscle fibers during the rise of tension in an isometric tetanus J. Physiol. 317, 207-221.

Daniel, T., 1984. Unsteady aspects of aquatic locomotion. Am. Zool. 24, 121-134.

Denny, M., 1993. Air and Water. Princeton University Press.

Emerson, S., De Jongh, H.J., 1980. Muscle activity at the ilio-sacral articulation of frogs. J. Morphol. 166, 129-144.

Full R.J., Koditschek D.E., 1999. Templates and anchors: neuromechanical hypotheses of legged locomotion on land. J. Exp. Biol. 202, 3325-3332.

Gillis, G., Biewener, A., 2000. Hind limb extensor muscle function during jumping and swimming in the toad (Bufo marinus). J. Exp. Biol. 203, 3547-3563.

Gillis, G., Blob, R., 2001. How muscles accomodate movement in different physical environments: aquatic vs. terrestrial locomotion in vertebrates. Comp. Bioch. Phys. 131, 6175.

Hughes, W., Brighton, J., 1999. Fluid dynamics (3th edition). McGraw-Hill, New York.

Johansson, C., Lauder, G., 2004. Hydrodynamics of surface swimming in leopard frogs (Rana pipiens). J. Exp. Biol. 207, 3945-3958. 
Kargo, W., Nelson, F., Rome, L., 2002. Jumping in frogs: assessing the design of the skeletal system by anatomically realistic modeling and forward dynamic simulation. J. Exp. Biol. 205: 1683-1702.

Kargo, W., Rome, L., 2002. Functional morphology of proximal hindlimb muscles in the frog Rana pipiens. J. Exp. Biol. 205, 1987-2004.

Kamel, L.T., Peters, S.E., Bashor, D.P., 1996. Hopping and swimming in the leopard frog, Rana pipiens. 2. A comparison of muscle activities. J. Morphol. 203, 17-31.

Lieber, R., Brown, C., 1992. Sarcomere length - joint angle relationships of seven frog hindlimb muscles. Acta Anat. 145, 289-295.

Lutz, G., Rome, L., 1994. Built for jumping: the design of the frog muscular system. Science 263, 370-372.

Marsh, R., 1994. Jumping ability of anuran amphibians. Adv. Vet. Sci. Comp. Med. 38, 51111.

Nauwelaerts, S., Aerts, P., 2003. Propulsive impulses as a covarying performance measure in the comparison of the kinematics of swimming and jumping in frogs. J. Exp. Biol. 206, 43414351 .

Nauwelaerts, S., Scholliers, J., Aerts, P., 2004. A functional analysis of how frogs jump out of the water. Biol. J. Linnean Soc. 83, 413-420.

Nauwelaerts, S.,Stamhuis, E., Aerts, P., 2005a. Swimming and jumping in a semi-aquatic frog, Rana esculenta. Anim. Biol. 55, 3-15.

Nauwelaerts, S., Stamhuis, E., Aerts, P., 2005b. Propulsive force calculations in swimming frogs I. A momentum-impulse approach. J. Exp. Biol. 208, 1445-1451.

Nauwelaerts, S., Aerts, P., 2006. Take-off and landing forces in jumping frogs. J. Exp. Biol. $209: 66-77$.

Nauwelaerts, S., Ramsay, J., Aerts, P., 2007. Morphological correlates of aquatic and terrestrial locomotion in a semi-aquatic frog, Rana esculenta: no evidence for a design conflict. J. Anat. 210, 304-317

Nishikawa, K., Biewener, A., Aerts, P., Ahn, A., Chiel, H., Daley, M., Daniel, T., Full, R., Hale, M., Hedrick, T., Lappin, K., Nichols, R., Quinn, R., Satterlie, R., Szymik, B., 2007. Neuromechanics: An integrative approach for understanding motor control. Integr. Comp. Biol. 47, 16-54.

Olson, J., Marsh, R., 1998. Activity patterns and length changes in hindlimb muscles of the bullfrog Rana catesbeiana during jumping. J. Exp. Biol. 201, 2763-2777.

Peplowski, M., Marsh, R., 1997. Work and power output in the hindlimb muscles of Cuban tree frogs Osteopilus septentrionalis during jumping. J. Exp. Biol. 200, 2861-2870. 
Richards, C., 2008. The kinematic determinants of anuran swimming performance: an inverse and forward dynamics approach. J. Exp. Biol. 211, 3181-3194.

Roberts, T., Marsh, R., 2003. Probing the limits to muscle-powered accelerations: lessons from jumping bullfrogs.J. Exp. Biol. 206, 2567-2580.

Stamhuis, E, Nauwelaerts, S., 2005. Propulsive force calculations in swimming frogs II. Application of a vortex ring model to DPIV data. J. Exp. Biol. 208, 1445-1451.

Wilson, R., Franklin, C., James, R., 2000. Allometric scaling relationships of jumping performance in the striped marsh frog Limnodynastes peronii. J. Exp. Biol. 203, 1937-1946.

Woledge, R., Curtin, C., Homsher, E. 1985. Energetic aspects of muscle contraction. Academic Press. 
Table 1: morphometrics used as model input (from Nauwelaerts et al., 2004).

\begin{tabular}{|l|l|}
\hline Body mass & $0.02 \mathrm{~kg}$ (entire mass concentrated in ellipsoid) \\
\hline Snout-vent length (SVL) (snout - cloaca) & $0.05 \mathrm{~m}$ (length of ellipsoid) \\
\hline Thigh length (hip - knee) & $0.025 \mathrm{~m}$ \\
\hline Shank length (knee - ankle) & $0.024 \mathrm{~m}$ \\
\hline $\begin{array}{l}\text { (Tarsal)+metatarsal length (ankle - } \\
\text { metatarsal-phalangeal joint) }\end{array}$ & $0.015 \mathrm{~m}$ \\
\hline Longest toe length & $0.029 \mathrm{~m}$ \\
\hline \multicolumn{1}{|c|}{ Total hind limb length } & $0.093 \mathrm{~m}\left(\sum\right.$ thigh, shank, (tarsal), metatarsal, toe $)$ \\
\hline \multicolumn{1}{|c|}{ Total foot length } & $0.044 \mathrm{~m}\left(\sum(\right.$ tarsal $)$, metatarsal,toe $)$ \\
\hline Foot surface area (web area) & $0.00038 \mathrm{~m}^{2}$ \\
\hline Ellipsoid short axis (calculated) & $0.011 \mathrm{~m}\left(\right.$ Foot surface area $\left.=\pi \frac{\text { foot length short axis }}{2}\right)$ \\
\hline
\end{tabular}




\section{Figure legends}

Figure 1: Diagrammatic representation of the movement of body and feet of the model. A: stylised outline of Rana esculenta; B: Model at maximal actuator 'flexion'; C: Model at maximal actuator extension.

Figure 2 A: The velocity dependency of the force output of the actuator; B: Time dependency of activation level of the actuator.

Figure 3: Output of the reference jump and swimming kick. A: bold lines are actuator forces for jumping (green) and swimming (red); thin lines represented (negated) resistive forces (see text; green $=$ in jumping, blue $=$ on the feet in swimming, black = on the body in swimming); B: Velocities of body and feet for jumping (green) and swimming (red); C: Displacements of body and feet for jumping (green) and swimming (red). The vertical dashed line refers to the instant of full activation of the actuator.

Figure 4: Propulsive impulses during jumping and swimming. Squares refer to in vivo measurements (taken from Nauwelaerts and Aerts, 2003); dots to the model output of the reference jump and swimming kick.

Figure 5 A: Actuator velocity for the reference jump (green) and swimming kick (red); B : force-velocity relationship of the actuator (black) and the force-velocity maps as occurring during the reference jump (green) and swimming kick (red); C : relative extension speed against relative time for a real representative jump and swimming cycle in Rana esculenta (measured as the difference in speed between ankle and snout; extracted from data set collected by Nauwelaerts and Aerts, 2003). 
Figure 1

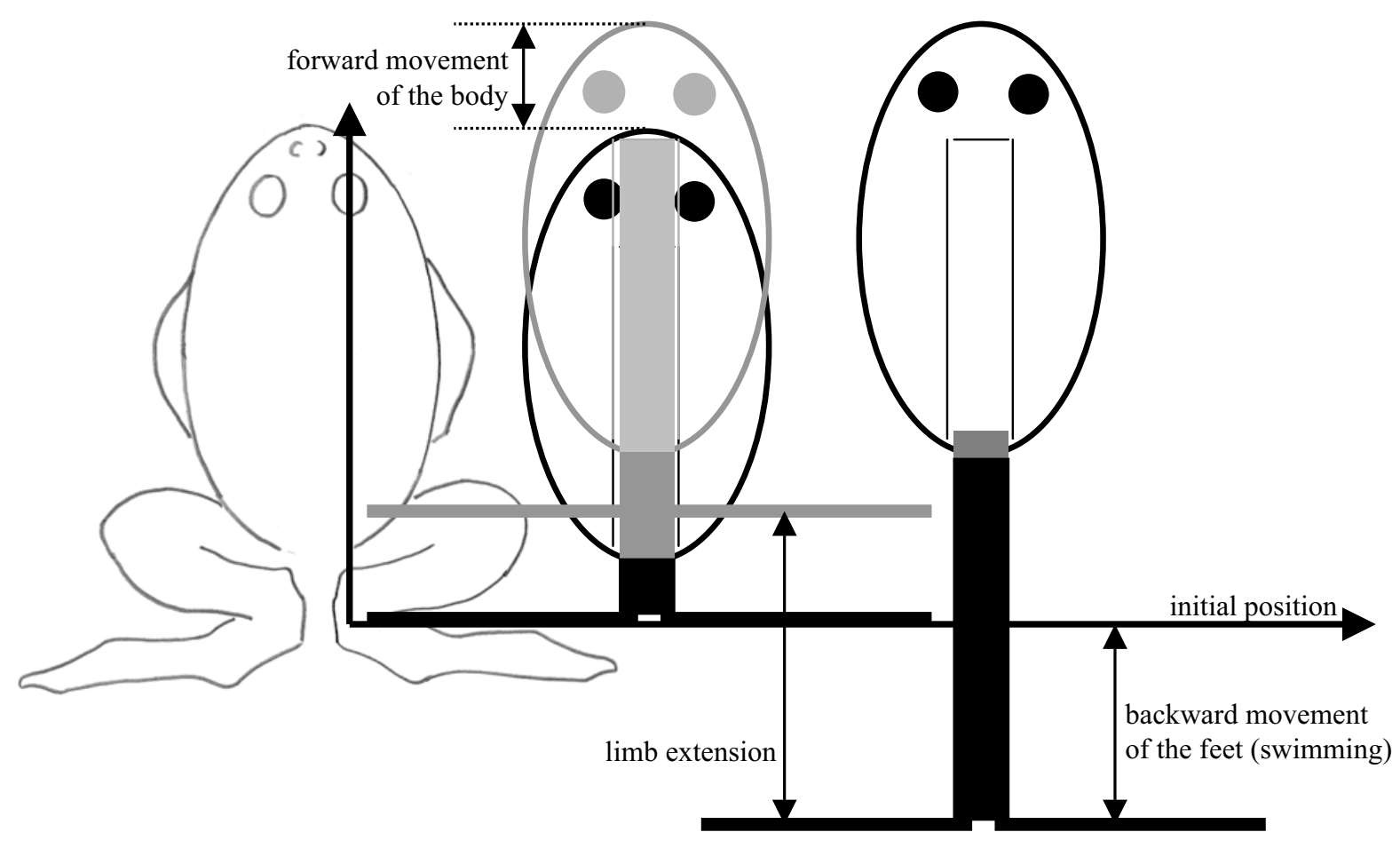


Figure 2
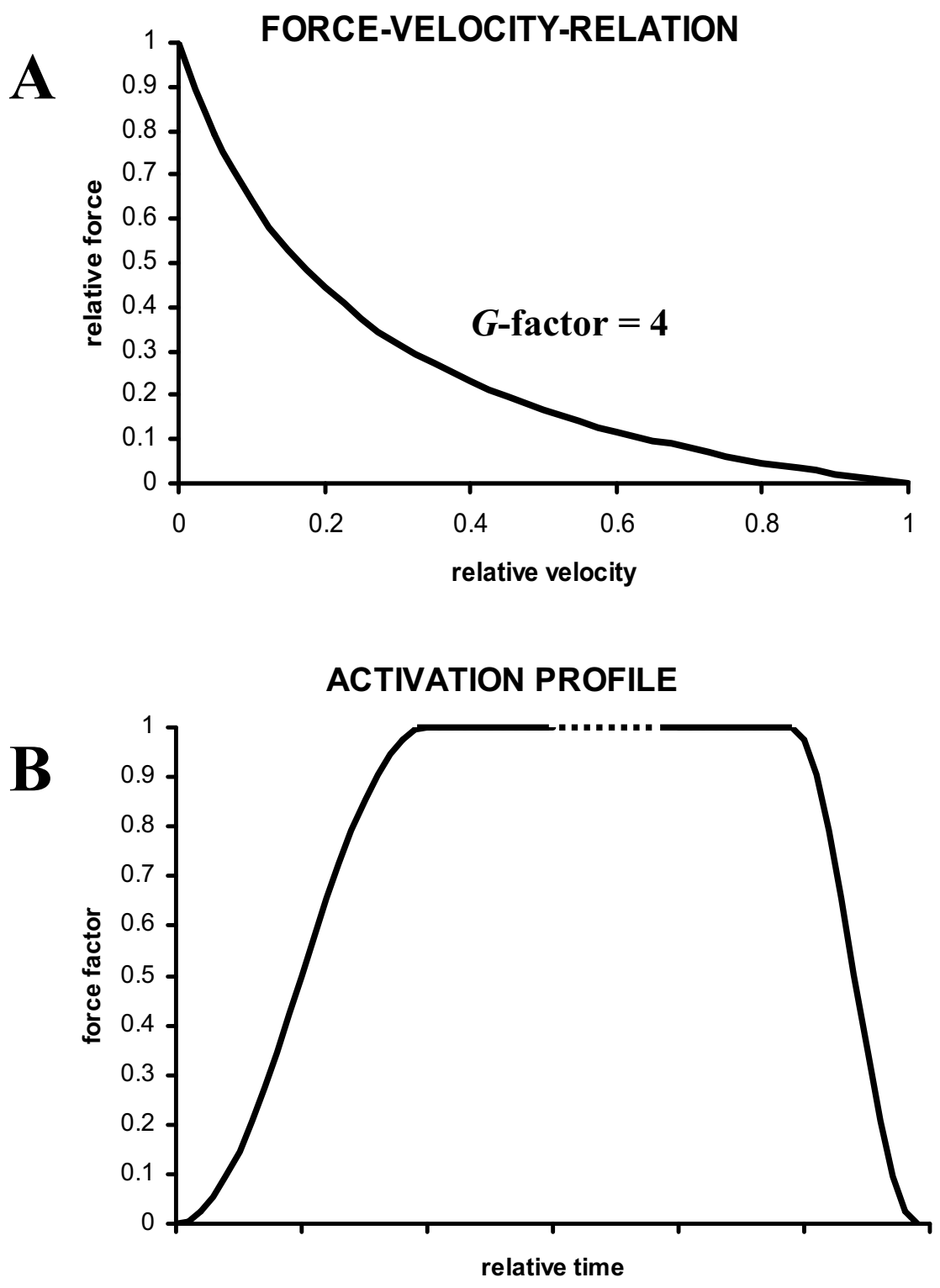
Figure 3

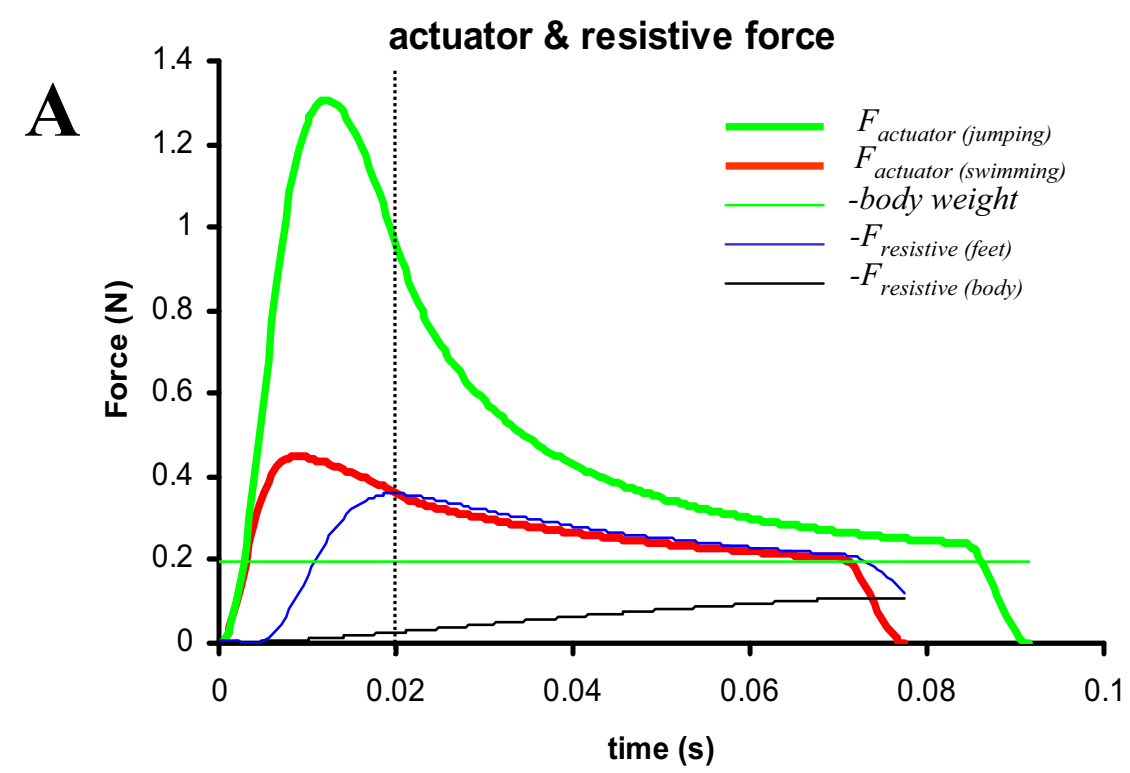

B
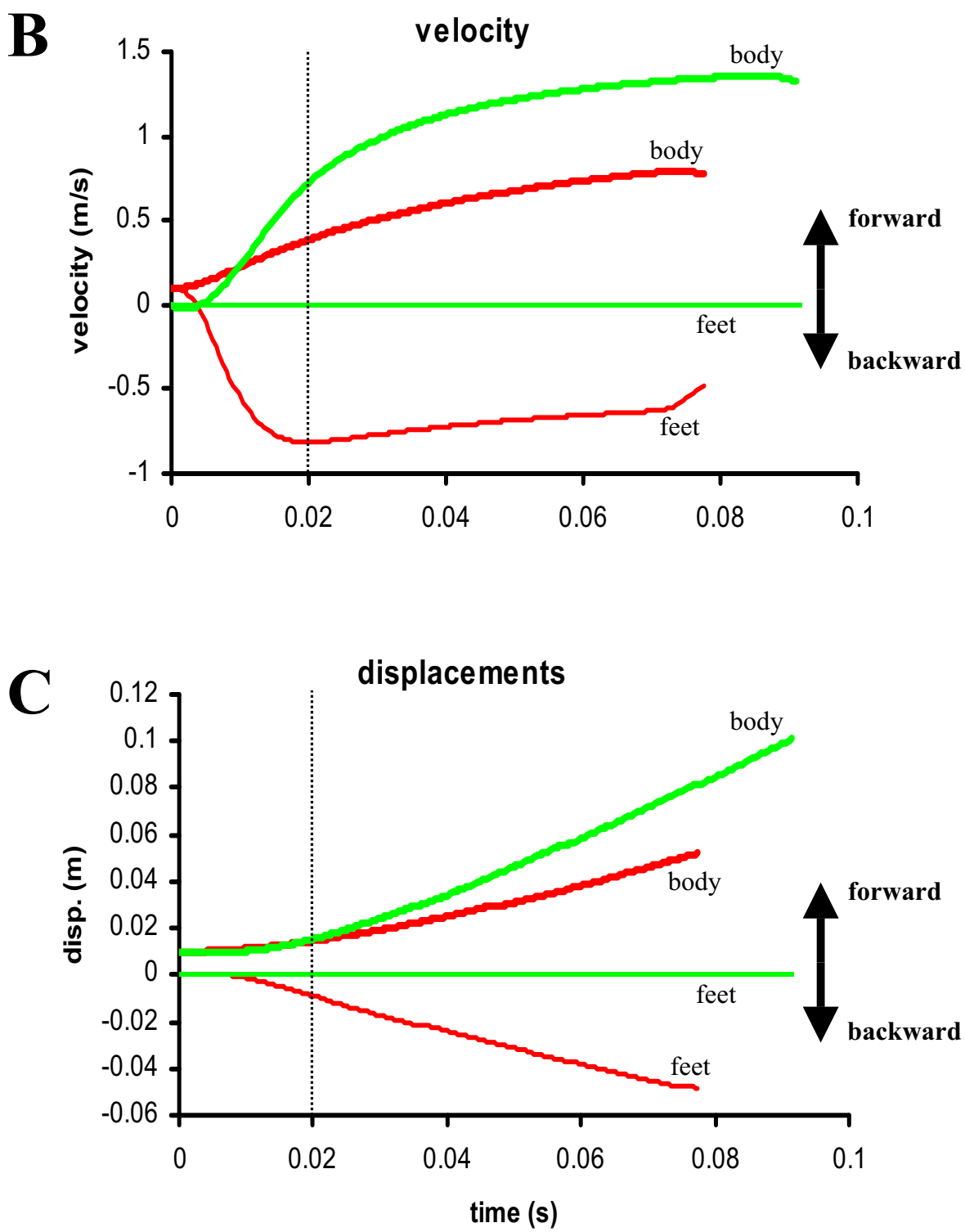
Figure 4

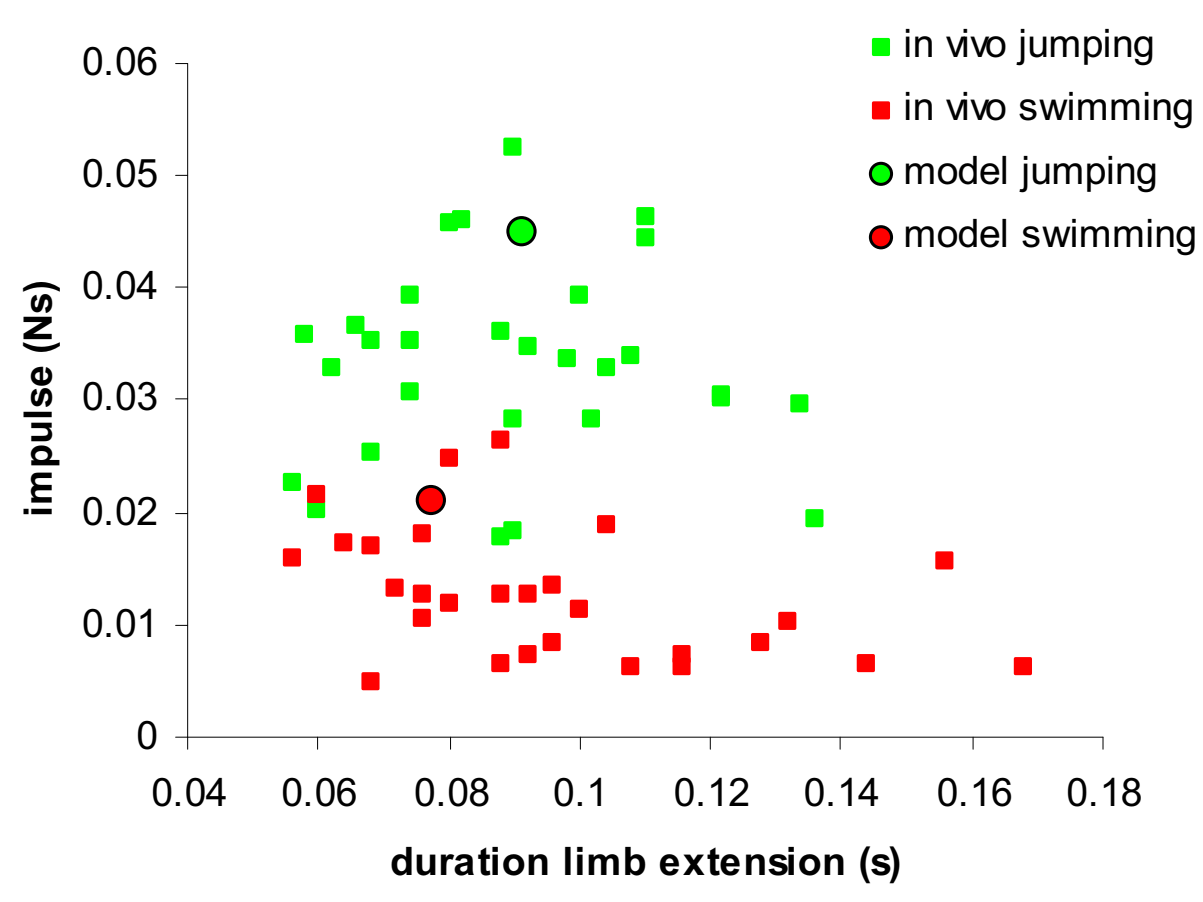


Figure 5
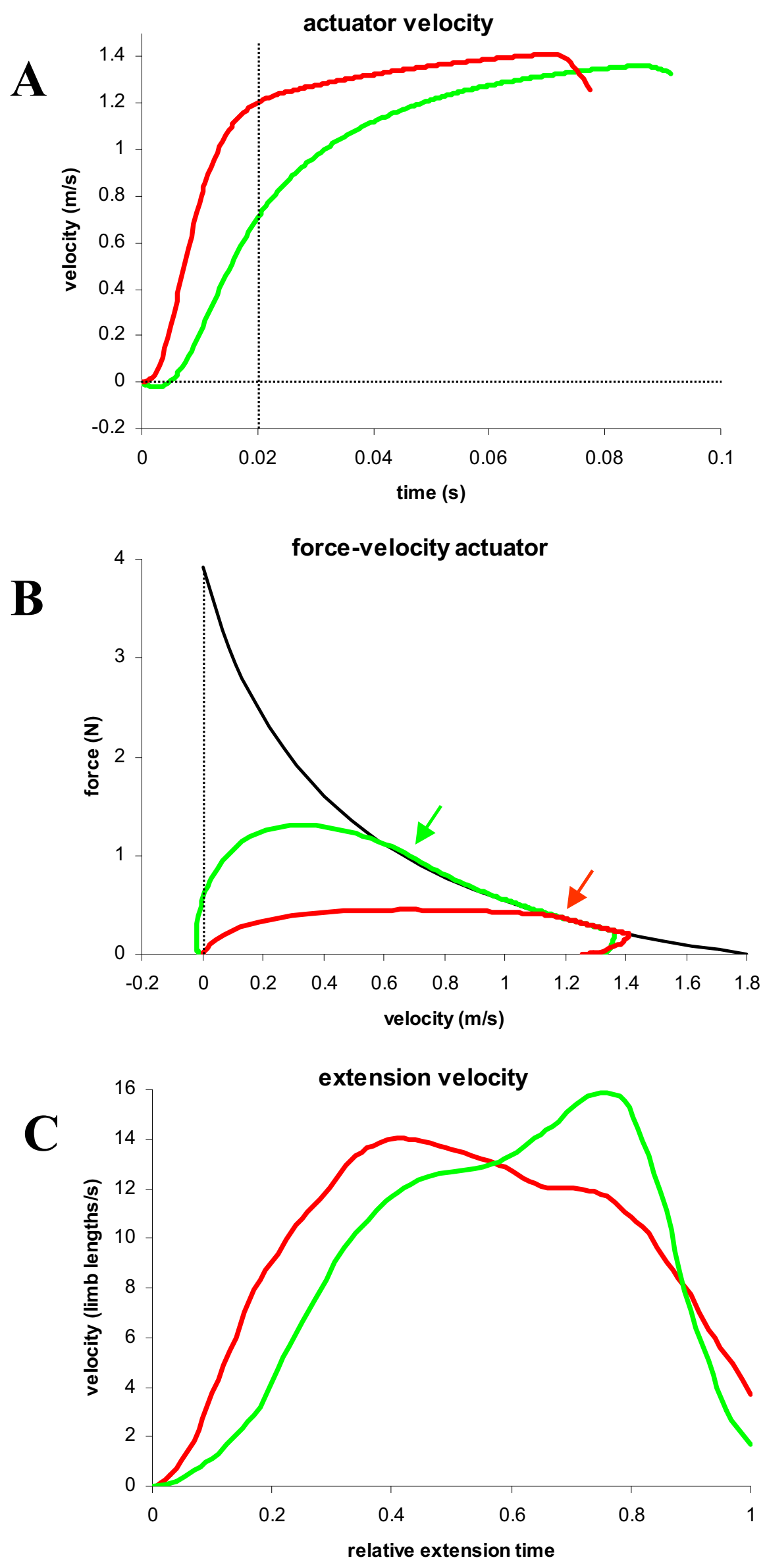